\title{
Antiviral effects of dehydroascorbic acid
}

\author{
MISAO UOZAKI ${ }^{1}$, KEIKO IKEDA $^{1}$, KAZUKO TSUJIMOTO $^{1}$, MITSUNORI NISHIDE $^{1}$, \\ HISASHI YAMASAKI $^{1}$, BOONRUANG KHAMSRI ${ }^{2}$ and A. HAJIME KOYAMA ${ }^{1}$
}

\author{
${ }^{1}$ Division of Virology, Department of Cellular and Molecular Medicine, Wakayama Medical University \\ Graduate School of Medicine, Wakayama 641-0011, Japan; ${ }^{2}$ Department of Microbiology and Parasitology, \\ Faculty of Medical Science, Naresuan University, Phitsanulok 65000, Thailand
}

Received May 13,2010; Accepted August 2, 2010

DOI: $10.3892 / \mathrm{etm} .2010 .139$

\begin{abstract}
In the present study, dehydroascorbic acid inhibited the multiplication of viruses of three different families: herpes simplex virus type 1 (HSV-1), influenza virus type A and poliovirus type 1. Although dehydroascorbic acid showed some cytotoxicity at higher concentrations, the observed antiviral activity was not the secondary result of the cytotoxic effect of the reagent, as the inhibition of virus multiplication was observed at reagent concentrations significantly lower than those resulting in cytotoxicity. Characterization of the mode of the antiviral action of dehydroascorbic acid against HSV-1 revealed that the addition of reagent at any time post infection inhibited the formation of progeny infectious virus in the infected cells, and a one-step growth curve showed that the addition of reagent allowed formation for an additional $2 \mathrm{~h}$, but then almost completely suppressed it. These results indicate that the reagent inhibits HSV-1 multiplication after the completion of viral DNA replication, probably at the step of the envelopment of viral nucleocapsids at the Golgi apparatus of infected cells.
\end{abstract}

\section{Introduction}

During the course of studies on the antiviral activities of various natural products and their components (1-6), we previously characterized the antiviral activity of ascorbic acid against the multiplication of a variety of DNA and RNA viruses under the defined in vitro conditions. We found that the antiviral activity of ascorbic acid was not due to its antioxidant activity since dehydroascorbic acid, an oxidized form of ascorbic acid without any reducing ability, also showed noticeable antiviral activities against those viruses

Correspondence to: Dr A. Hajime Koyama, Division of Virology, Department of Cellular and Molecular Medicine, Wakayama Medical University Graduate School of Medicine, 580 Mikazura, Wakayama 641-0011, Japan

E-mail: koyama@wakayama-med.ac.jp

Key words: dehydroascorbic acid, herpes simplex virus type 1, influenza virus, poliovirus, antiviral
(5). Previous characterization revealed that dehydroascorbic acid showed even stronger antiviral activity, though a much less cytotoxic effect in vitro than ascorbic acid. In addition, dehydroascorbic acid does not induce the formation of highly toxic free hydroxyl radicals, even in the presence of metal ions in culture medium. Considering a potential therapeutic use of dehydroascorbic acid, we further characterized the mode of antiviral activities of this compound.

\section{Materials and methods}

Cells and viruses. MDCK, HEp-2 and Vero cells were grown in Eagle's minimum essential medium (MEM) containing 5\% fetal bovine serum (FBS). Herpes simplex virus type 1, strain $\mathrm{F}(\mathrm{HSV}-1)$, influenza virus A/Aichi $\left(\mathrm{H}_{3} \mathrm{~N}_{2}\right)$ and poliovirus type 1 , Sabin vaccine strain, were used throughout the experiments. The viruses were propagated in Vero cells (for HSV-1 and poliovirus) in MEM supplemented with 0.5\% FBS, or in MDCK cells (for influenza virus) in MEM supplemented with $0.1 \%$ bovine serum albumin (BSA) and acetylated trypsin $(4 \mu \mathrm{g} / \mathrm{ml})$. The viruses were stored at $-80^{\circ} \mathrm{C}$ until use. The amount of each virus was measured by a plaque assay as described previously (7-9).

Effect of the reagent on the virus yields. Dehydroascorbic acid was obtained from Wako Chemicals. The reagent solution $(1.0 \mathrm{M}$ or $100 \mathrm{mM})$ was prepared by dissolving the reagents in hot water, and its acidity was neutralized with $1 \mathrm{~N}$ sodium hydroxide solution followed by filtration through a Millipore Dimex membrane (pore size, $0.22 \mu \mathrm{m}$ ).

Monolayered cells in 35-mm dishes were infected with the viruses at an indicated multiplicity of infection (MOI). The infected cells were further incubated at $37^{\circ} \mathrm{C}$ (for HSV-1 and influenza virus) or $35.5^{\circ} \mathrm{C}$ (for poliovirus) for the indicated times in the serum-free MEM containing 0.1\% BSA and the indicated concentrations of the reagent. For the experiments with influenza virus, acetylated trypsin $(4 \mu \mathrm{g} / \mathrm{ml})$ was also added to the medium for the proteolytic activation of virus infectivity. At the indicated times, the infected cells with the culture medium (for HSV-1 and poliovirus) or the culture medium only (for influenza A virus) were harvested, and the amount of total progeny virus in the culture was determined as described previously (7-9). 
Determination of cytopathic effects and cell death. Confluent monolayers of HEp-2 cells were incubated at $37^{\circ} \mathrm{C}$ for $24 \mathrm{~h}$ in the serum-free MEM containing 0.1\% BSA and the indicated concentrations of reagent. Cytopathic effects were determined by microscopic observation of the cells, in which approximate numbers of rounded cells on monolayers were estimated under a phase-contrast microscope.

To determine the extent of cell death, the monolayered cells were trypsinized to obtain a single-cell suspension. After the addition of MEM containing 5\% FBS to the suspension to neutralize the trypsin and to stabilize the cells, the number of living or dead cells was determined by a dye-exclusion method with trypan blue.

\section{Results and Discussion}

Effect of dehydroascorbic acid on the multiplication of DNA and RNA viruses. In a previous study (5), we found that dehydroascorbic acid had antiviral activity against HSV-1 in vitro, which was stronger than that of ascorbic acid. To further characterize the antiviral activities of the reagent, we tested three viruses of completely different types: HSV-1 (Family of Herpesviridae), influenza virus type A (Family of Orthomyxoviridae) and poliovirus (Family of Picornaviridae). HSV-1 is a double-stranded DNA virus (10), while influenza virus is a negative-stranded RNA virus (11); both are large enveloped viruses and require the cell nucleus for virus multiplication. By contrast, poliovirus is a small non-enveloped virus carrying a positive-stranded RNA as a genome, and replicates in the cytoplasm of infected cells (12).

Fig. 1 shows the effects of dehydroascorbic acid on the relative virus yields of these three viruses when the cells infected with each of the viruses were incubated in the medium containing the indicated concentrations of the reagent. The multiplication of all three viruses was suppressed to various degrees depending on the virus, although these viruses showed a similar degree of sensitivity to ascorbic acid as in the previous study (5). The virus yield decreased with increasing concentrations of dehydroascorbic acid: with $10 \mathrm{mM}$ of the reagent, the yield of influenza virus, HSV-1 and poliovirus was approximately one thousandth, one tenth and half that in the absence of the reagent, respectively, indicating that influenza virus is the most sensitive and poliovirus is the least sensitive of these viruses. These results clearly show that dehydroascorbic acid inhibits the multiplication of viruses of widely different structures (regardless of whether they are enveloped or non-enveloped, double-stranded DNA- or single-stranded RNA-genome) and also that it inhibits virus multiplication whether the replication and transcription of the viral genome occur in the nucleus or in the cytoplasm of the infected cells. It is also worth noting that the antiviral activity of the reagent was apparently independent of the cell type, as the multiplication of the influenza virus was examined in MDCK cells (derived from canine kidney cells), while that of HSV-1 and poliovirus was examined in HEp-2 cells (derived from human cervical carcinoma).

Virucidal effect of the reagent. To examine the direct effect of dehydroascorbic acid on the infectivity of viruses, HSV-1 or poliovirus was incubated in the buffered solutions containing

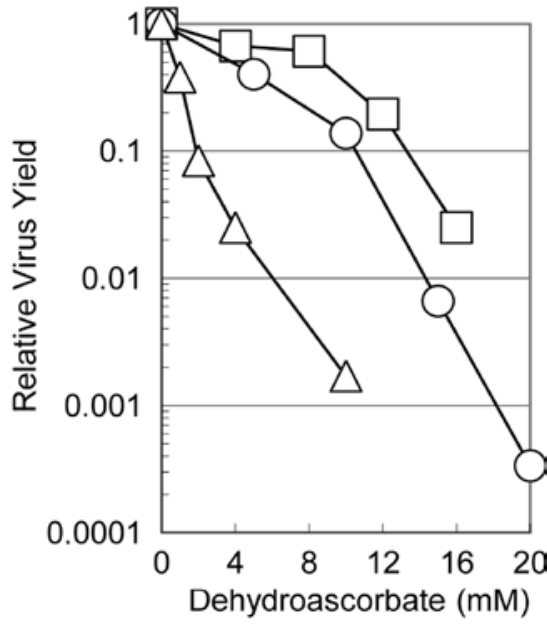

Figure 1. Effect of dehydroascorbic acid on the virus yields. Confluent monolayers of HEp-2 (for HSV-1 and poliovirus) or MDCK (for influenza virus) cells were infected with each of the viruses at an MOI of 10 for HSV-1 and 7 for influenza virus or poliovirus. The infected cells were incubated in the medium containing the indicated concentrations of dehydroascorbic acid at $37^{\circ} \mathrm{C}$ for $\mathrm{HSV}-1$ and influenza virus or at $35.5^{\circ} \mathrm{C}$ for poliovirus. At the end of infection, the amounts of infectious progeny viruses were determined and were normalized to the virus yield in the absence of the reagent. O, HSV-1; $\triangle$, influenza virus; $\square$, poliovirus.

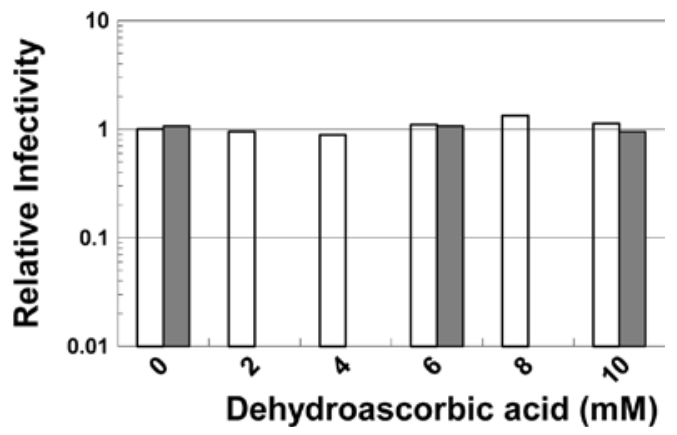

Figure 2. Virucidal effect of dehydroascorbic acid on HSV-1 and poliovirus. The virus was incubated on ice for $20 \mathrm{~min}$ in $10 \mathrm{mM}$ citrate buffer ( $\mathrm{pH} 4.0$ ) containing the indicated concentrations of dehydroascorbic acid. After the incubation, the amounts of infectious virus in the buffer were determined and were normalized to those in the absence of the reagent. Open bar, HSV-1; gray bar, poliovirus.

the reagent at various concentrations. As shown in Fig. 2, neither the infectivity of HSV-1 nor of poliovirus was inactivated by incubation with the reagent even at $10 \mathrm{mM}$, indicating that dehydroascorbic acid does not directly inactivate these viruses. Similar results were observed when the viruses were incubated in buffer at a neutral $\mathrm{pH}$ (data not shown).

Cytopathic effects of the reagent. Ascorbic acid is known to generate hydroxyl radicals, even in the presence of a trace amount of ferric ion in medium. We previously reported that ascorbic acid causes a severe cytotoxic effect in cells, probably due to these hydroxyl radicals (5). Since dehydroascorbic acid also induced a significant degree of cytopathic effects (cell rounding and detachment from the dish surface) on the virus-infected cells, we examined the effects of the reagent on the viability of the uninfected cells. As shown in Fig. 3, HEp-2 


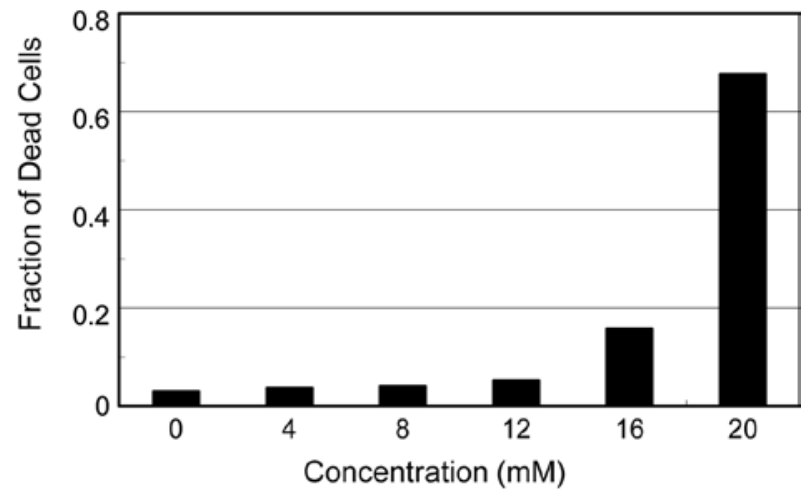

Figure 3. Effect of dehydroascorbic acid on the cell viability. Confluent monolayers of HEp-2 cells were incubated at $37^{\circ} \mathrm{C}$ in MEM containing $0.1 \%$ BSA and varying concentrations of dehydroascorbic acid. After incubation for $24 \mathrm{~h}$, the treated cells were trypsinized to obtain a single-cell suspension, and the amounts of living and dead cells in each culture were determined by a dye-exclusion test with trypan blue.

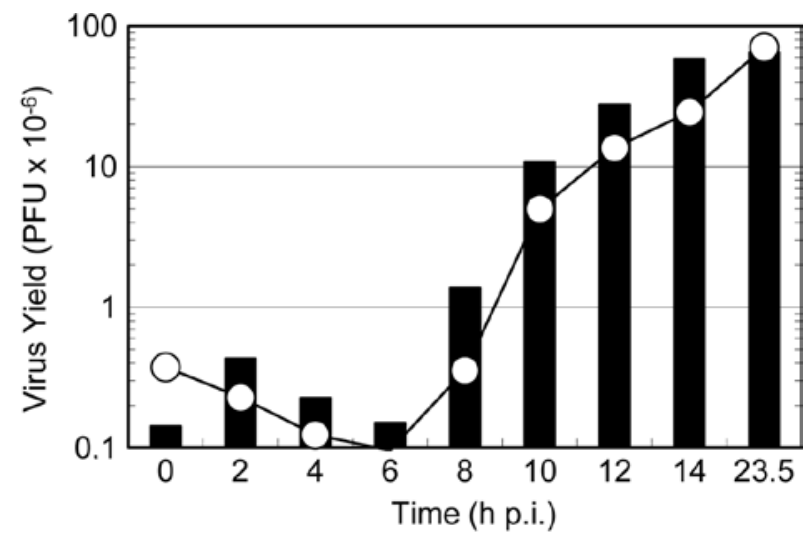

Figure 4. Effect of the time of addition of dehydroascorbic acid on virus yield. A group of confluent monolayers of HEp-2 cells was infected with HSV-1 at an MOI of 10 and incubated in MEM containing 0.1\% BSA. At the indicated times after infection i) the infected culture in one dish was harvested and the amount of the infectious virus was determined to reveal a one-step growth curve (open circle) and ii) dehydroascorbic acid was added to the culture medium in another dish at a final concentration of $10 \mathrm{mM}$. The infected cells were further incubated in the presence of the reagent, and the total progeny virus in each culture was harvested at $23.5 \mathrm{~h}$ p.i. to determine the amount of the final virus yield (black bar).

cells incubated in medium containing various concentrations of dehydroascorbic acid for $24 \mathrm{~h}$ showed no increase in the fraction of dead cells even at $12 \mathrm{mM}$ of reagent, although a significant amount of dead cells appeared at $16 \mathrm{mM}$ and increased drastically to approximately $70 \%$ at $20 \mathrm{mM}$. These results indicate that, although the reagent induces significant cytopathic effects on the virus-infected HEp-2 and MDCK cells, the cytotoxic effect of this reagent is likely insufficient to directly affect the multiplication of the viruses in the infected cells, considering the concentration of dehydroascorbic acid required for the significant antiviral activities, i.e., approximately $10 \mathrm{mM}$.

Dehydroascorbic acid-sensitive step in the HSV-1 multiplication. Previously, we quantitatively characterized the kinetics

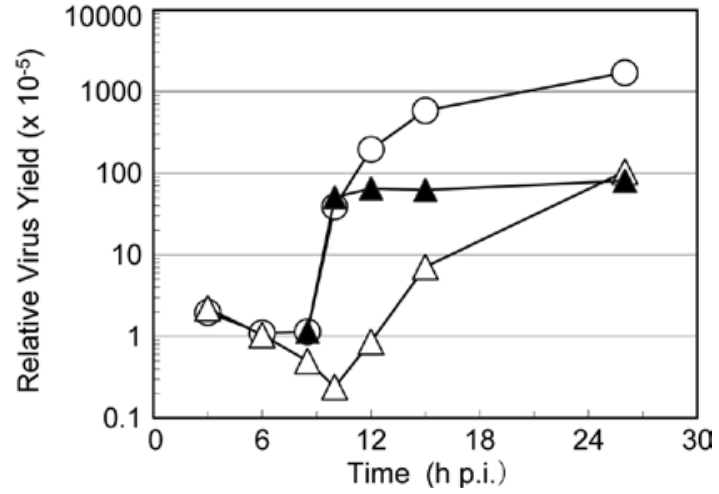

Figure 5. Effect of dehydroascorbic acid on the one-step growth curve of HSV-1. Confluent monolayers of HEp-2 cells were infected with HSV-1 at an MOI of 10 . The infected cells were incubated at $37^{\circ} \mathrm{C}$ for $26 \mathrm{~h}$ in MEM containing $0.1 \%$ BSA supplemented with $(\circ)$ or without $(\triangle) 10 \mathrm{mM}$ dehydroascorbic acid. A group of dishes $(\Delta)$ received the reagent at $8 \mathrm{~h}$ p.i. At the indicated time, the amounts of total infectious progeny viruses were determined.

of viral DNA replication, the encapsidation of viral DNA, the envelopment of nucleocapsids and the formation of infectious progeny virus in HSV-1-infected cells (13), and revealed that viral DNA replication occurs exclusively between 3 and $6 \mathrm{~h}$ post infection (p.i.) and that a large amount of DNA accumulates in the infected cells when the replication of the virus DNA is completed. The formation of nucleocapsids as well as the envelopment of these nucleocapsids begins at $5 \mathrm{~h}$ p.i., simultaneously with the formation of infectious progeny virus, and the amount of the progeny virus increases with time until approximately $14 \mathrm{~h}$ p.i.

To examine the target of the antiviral activity of dehydroascorbic acid in the multiplication process of HSV-1, a 'time of addition' experiment was carried out. As shown in Fig. 4, the reagents were added to the infected culture at various times after the infection, and the virus yield at the end of virus multiplication was compared to the virus yield at the time of the addition of reagent. The amounts of progeny virus were suppressed even when the infected cells received the reagent in the late stages of the infection, such as at 10 or $12 \mathrm{~h}$ p.i. A small but significant increase in the amount of progeny virus was observed after the addition of the reagent at any time point during infection, except at $0 \mathrm{~h} \mathrm{p.i}$; for example, the amount of the infectious virus at $10 \mathrm{~h}$ p.i. was 5.0. When dehydroascorbic acid was added at this time point and cell culture was continued for $23.5 \mathrm{~h}$, the final virus yield was 10.7, indicating that progeny virus formation continued. However, this value of 10.7 was much less than the virus yield without the addition of dehydroascorbic acid (70.4), though it was almost similar to the amount of the infectious virus formed at $12 \mathrm{~h}$ p.i. (13.6). Thus it is evident that, although the addition of dehydroascorbic acid did not completely stop progeny formation, it greatly suppressed the formation even when added at the late stages of infection. These results clearly show that i) the reagent interferes with virus multiplication even after the completion of viral DNA replication (i.e., at $6 \mathrm{~h}$ p.i.) and ii) the formation of progeny virus does not cease immediately after the addition of the reagent. 
To further clarify the mode of action of the reagent on viral multiplication, a one-step growth curve was examined in the presence of the reagent. As shown in Fig. 5, the addition of the reagent at the beginning of virus multiplication resulted in a significant delay in the onset of the progeny virus formation (i.e., an extension of the latent period) and decreased the final yield of progeny virus. By contrast, when the reagent was added at $8 \mathrm{~h}$ p.i., the formation of progeny virus continued steadily for an additional $2 \mathrm{~h}$ and then ceased completely. These results are consistent with the results in Fig. 4, indicating that the reagent inhibits virus multiplication even at the late stages of the virus multiplication, and that the formation of progeny infectious virus continues for $2 \mathrm{~h}$ after the addition of the reagent to the infected culture.

Previously, we observed similar kinetics when the multiplication of HSV-1 was inhibited by the addition of ammonium chloride (7) or Brefeldin A (14) at the stage of the envelopment of viral nucleocapsids after the completion of viral DNA replication. These two reagents are known to inhibit the function of the Golgi apparatus of cells where the envelopment of HSV nucleocapsids takes place (15). The similarity of the kinetics suggests that dehydroascorbic acid inhibits the formation of progeny infectious virus at the stage of the envelopment of nucleocapsids at the Golgi apparatus of the infected cells, although additional contribution of some other step(s) in the multiplication process cannot be excluded.

In this study, we showed that dehydroascorbic acid inhibits the multiplication of several viruses of widely different structures and replication strategies. Previous characterization of the antiviral effects of ascorbic acid (5) revealed that the antiviral effect of ascorbic acid is, at least in part, a secondary result of the cytotoxic effect of the reagent. In contrast to ascorbic acid, the antiviral effect of dehydroascorbic acid is not a secondary effect of cytotoxicity, but is more likely specific interference in a certain virus-cell interaction, probably due to its binding to the virus or to molecules involved in viral replication. The results shown in Figs. 4 and 5 reveal that dehydroascorbic acid interferes with the multiplication of HSV-1 after the completion of viral DNA replication, probably at the stage of the envelopment of nucleocapsids (i.e., the assembly of progeny virus particles). Dehydroascorbic acid has been reported to have the ability to bind to proteins $(16,17)$ and to inhibit certain kinases and enzymes (18-20), suggesting that it may inhibit certain protein(s) necessary for virus-host interactions, and may thereby interfere with virus multiplication.

\section{Acknowledgements}

The authors thank Dr Tsutomu Arakawa for stimulating discussions and for assistance with manuscript editing.

\section{References}

1. Uozaki M, Yamasaki H, Katsuyama Y, Higuchi M, Higuchi T and Koyama AH: Antiviral effect of octyl gallate against DNA and RNA viruses. Antiviral Res 73: 85-91, 2007.

2. Yamasaki H, Uozaki M, Katsuyama Y, Utsunomiya $H$, Arakawa T, Higuchi M, Higuti T and Koyama AH: Antiviral effect of octyl gallate against influenza and other RNA viruses. Int J Mol Med 19: 685-688, 2007.

3. Utsunomiya H, Ichinose M, Uozaki M, Tsujimoto K, Yamasaki H and Koyama AH: Antiviral activities of coffee extracts in vitro. Food Chem Toxicol 46: 1919-1924, 2008.

4. Murayama M, Tujimoto K, Uozaki M, Katsuyama Y, Yamasaki H, Utsunomiya $\mathrm{H}$ and Koyama AH: Effect of caffeine on the multiplication of DNA and RNA viruses. Mol Med Rep 1: 251-255, 2008.

5. Furuya A, Uozaki M, Yamasaki H, Arakawa T, Arita M and Koyama AH: Antiviral effects of ascorbic acid and dehydroascorbic acids in vitro. Int J Mol Med 22: 541-545, 2008.

6. Tsujimoto K, Sakuma C, Uozaki M, Yamasaki H, Utsunomiya H, Oka $\mathrm{K}$ and Koyama AH: Antiviral effect of pyridinium formate, a novel component of coffee extracts. Int J Mol Med 25: 459-463, 2010.

7. Koyama AH and Uchida T: The effect of ammonium chloride on the multiplication of herpes simplex virus type 1 in Vero cells. Virus Res 13: 271-282, 1989.

8. Kurokawa M, Koyama AH, Yasuoka S and Adachi A: Influenza virus overcomes apoptosis by rapid multiplication. Int $\mathrm{J}$ Mol Med 3: 527-530, 1999.

9. Koyama AH, Irie H, Ueno F, Ogawa M, Nomoto A and Adachi A: Suppression of apoptotic and necrotic cell death by poliovirus. J Gen Virol 82: 2965-2972, 2001.

10. Roizman B and Knipe DM: Herpes simplex virus and their replication. In: Fields Virology. 4th edition. Fields BN, Knipe DM and Howley PM (eds). Lippincott-Raven, New York, pp2399-2460, 2001.

11. Lamb RA and Kruchikokug RM: Orthomyxoviridae: the viruses and their replication. In: Fields Virology. 4th edition. Fields BN, Knipe DM and Howley PM (eds). Lippincott-Raven, New York, pp1487-1530, 2001.

12. Racaniello VR: Picornaviridae: the viruses and their replication. In: Fields Virology. 4th edition. Fields BN, Knipe DM and Howley PM (eds). Lippincott-Raven, New York, pp685-722, 2001.

13. Koyama AH and Uchida T: Quantitative studies on the maturation process of herpes simplex virus type 1 in Vero cells. Virus Res 10: 281-286, 1988.

14. Koyama AH and Uchida T: Inhibition by Brefeldin A of the envelopment of nucleocapsids in herpes simplex virus type 1-infected Vero cells. Arch Virol 135: 305-317, 1994.

15. Leuzinger H, Ziegler U, Schraner EM, Fraefel C, Glauser DL, Heid I, Achermann M, Mueller M and Wild P: Herpes simplex virus 1 envelopment follows two diverse pathways. J Virol 79: 13047-13059, 2005.

16. Meucci E, Martorana GE, Ursitti A, Miggiano GA, Mordente A and Castelli A: Vitamin C-bovine serum albumin binding behavior. Ital J Biochem 36: 75-81, 1987.

17. Lozinsky E, Novoselsky A, Glaser R, Shames AI, Likhtenshtein GI and Meyerstein D: Effect of ionic strength on the binding of ascorbate to albumin. Biochim Biophys Acta 1571: 239-244, 2002.

18. Fiorani M, De Sanctis R, Scarlatti F, Vallorani L, De Bellis R, Serafini G, Bianchi M and Stocchi V: Dehydroascorbic acid irreversibly inhibits hexokinase activity. Mol Cell Biochem 209: 145-153, 2000.

19. Neault JF, Benkiran A, Malonga H and Tajmir-Riahl HA: The effects of anions on the solution structure of Na, K-ATPase. J Biomol Struc Dyn 19: 95-102, 2001.

20. Carcamo JM, Pedraza A, Borquez-Ojeda O, Zhang B, Sanchez R and Golde DW: Vitamin C is a kinase inhibitor: dehydroascorbic acid inhibits IkappaBalpha kinase beta. Mol Cell Biol 24: 6645-6652, 2004. 